\title{
Chromoblastomycosis: Report of a case from a non-endemic region
}

\section{Olfa El Amine El Hadj', Issam Msakni², Fehmi Lamine', Besma Laabidi², Ammar Bouzaiène ${ }^{2}$}

${ }^{1}$ Immuno-Histo-Pathological Department Salah Azaiez Institute, Tunis, Tunisia, ${ }^{2}$ Pathological Department, Military Hospital, Tunis, Tunisia

Corresponding author: Dr. Olfa El Amine El Hadj, E-mail: olfaelamine@yahoo.fr

Sir,

Chromoblastomycosis is a chronic fungal infection prevalent in tropical regions, but rare in Tunisia. It causes some diagnostic difficulties. We report the third case of a Tunisian man.

A 47-year-old man presented with a skin lesion, of 3 years duration, located in the right limb. The lesion gradually expanded to form a $20 \mathrm{~cm}$ violet-colored papule with an atrophic center (Fig. 1). The diagnosis of cutaneous tuberculosis was suspected. Cultures were negative. A deep skin biopsy revealed the presence of fungal elements within a granulomatous reaction (Figs. 2 and 3). There was no evidence of any immunodeficiency.

In the Maghreb countries, chromomycosis is rare. Among 30 observations of deep mycoses in Morocco, only 5 patients presented chromomycosis [1]. Eight cases have been reported in Algeria [2]. In Tunisia, only two cases were reported $[3,4]$.

The primary lesion is thought to develop as a result of percutaneous traumatic inoculation [5]. This is the case of our patient. Indeed, he was a victim of limb traumatism with inoculation of wood in the area of the lesion.

The disease affects predominantly men. Typical lesions grow slowly over many years and tend to be found on the lower limbs. The morphology of the lesion may be tumor, nodular, verrucous, plaque-like, psoriasiform, and papule as in our case or scar [6].

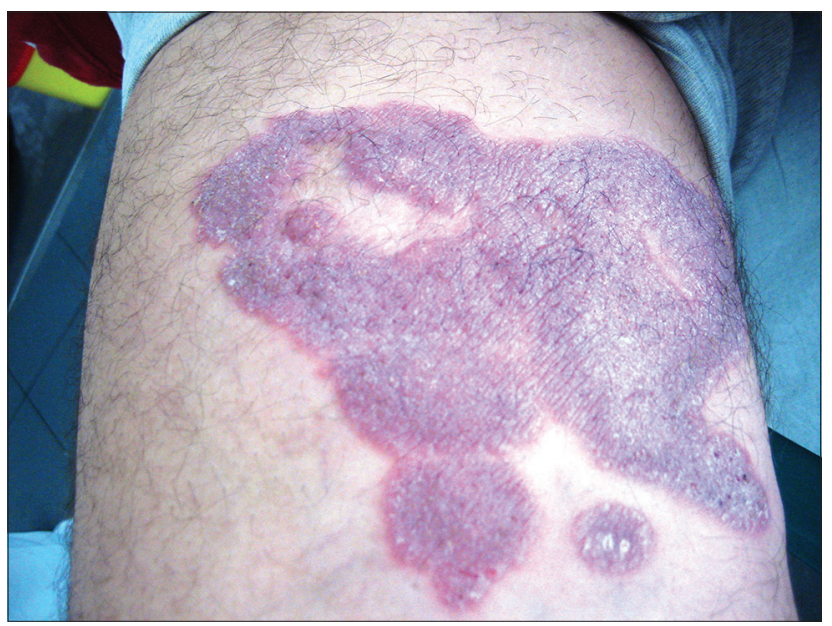

Figure 1: Violet-colored papule with an atrophic center.

In our country chromomycosis lesions may be confused with leishmaniasis, verrucous tuberculosis, and tertiary syphilis [3,4]. Mycologic tests are used to confirm the diagnosis. The principal causal agent is Fonsecaea pedrosoi, followed by four species in order of frequency, Phialophora verrucosa, Cladosporium carrionii, Fonsecaea compacta, and Rhinocladiella aquaspera $[6,7]$.

Histologic appearances are hyperkeratosis, pseudoepitheliomatous hyperplasia and granulomas in the upper and mid dermis. The granulomas are mostly of tuberculoid type, although a few suppurative granulomas are present. Intraepidermal microabscesses are often present. There is a background infiltrate of chronic inflammatory cells, and sometimes a few eosinophils, in the upper dermis, round, thick-walled, golden brown cells (sclerotic bodies, muriform cells,

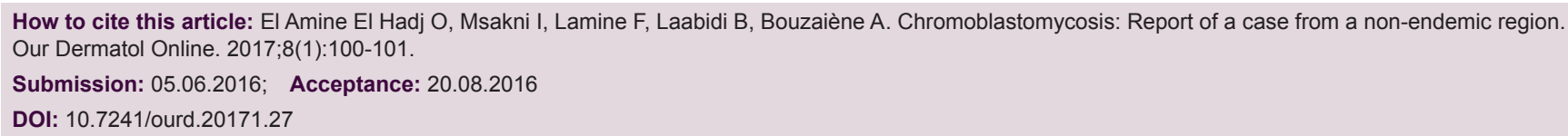




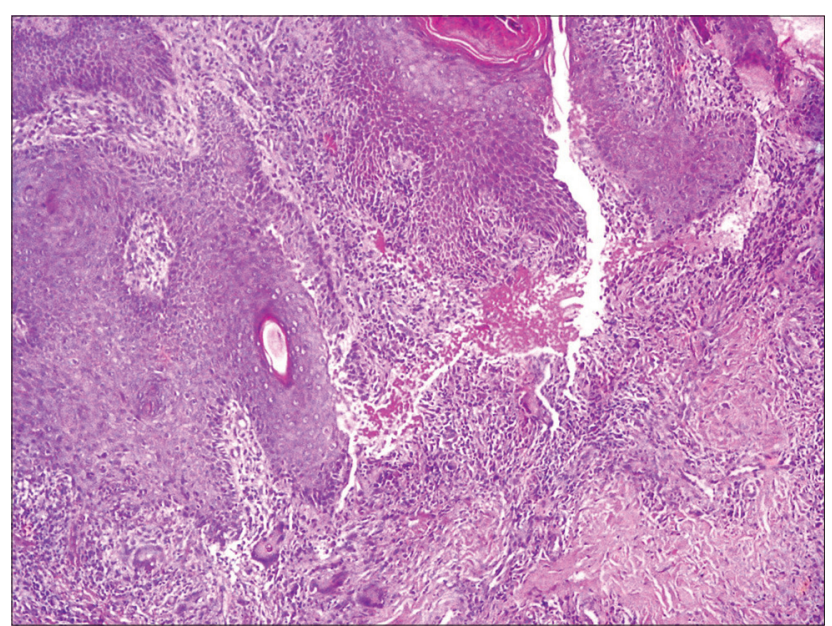

Figure 2: Biopsy showed hyperpasic epidermis within a granulomatous reaction in the dermis.

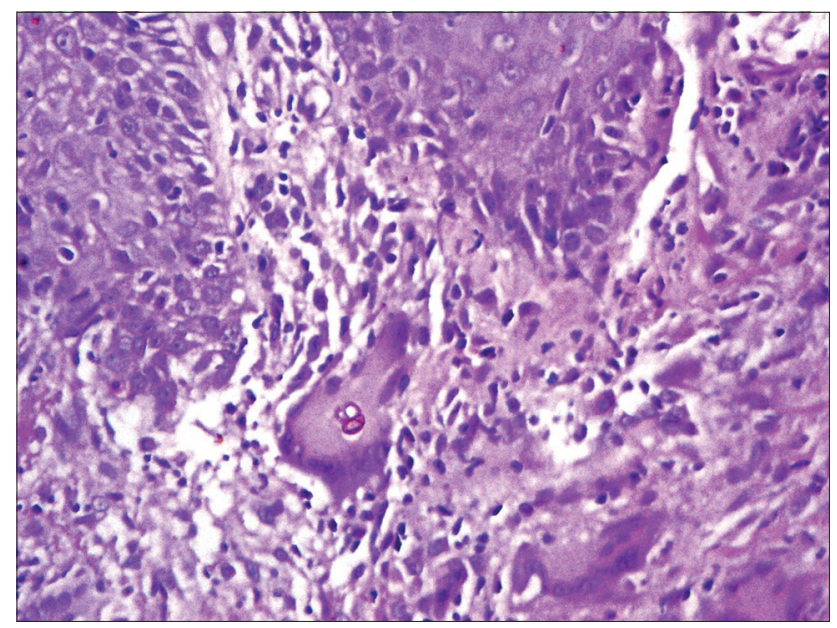

Figure 3: A deep skin biopsy revealed the presence of fungal elements.

medlar bodies) 5-12 micrometer can be seen in giant cells and lying free in the epidermal microabscesses. These sclerotic bodies are usually seen readily in heamatoxylin and eosin preparations and particularly in sections stained with hematoxylin alone $[2,5,8]$.

If not diagnosed and treated early, chromomycosis has a chronic evolutional course. The most frequent complication was secondary bacterial infection. Chronic chromomycosis also has potential association with epidermoid carcinoma ( 14 cases are reported in the literature) $[8,9]$ and also with skin melanoma [10].
Central nervous system invasion is possible and may be fatal [11].

Treatment in localized lesions can be surgical. Widespread lesions and long-standing cases can be treated medically [12]

Finally, Chromomycosis is quite rare in our country. Anatomopathologists should be aware of this diagnosis.

\section{REFERENCES}

1. Jarmouni R, Ntidam H, Afailal A et al. Les mycoses profondes (À propos de 30 cas). Rapports du XIXè Congrès de l'Association des Dermatologistes et Syphiligaraphes de Langue Française, Rabat, 12-15 mai 1989:39-43.

2. Boughdène-Stambouli $\mathrm{C}$, Belbachir $\mathrm{OH}$, Bariout $\mathrm{H}$. La chromomycose: A propos de 7 cas. Ann Dermatol Venereol. 2001;128:S21-7,C29.

3. Marrak H, Mnajaa N, Fenniche S, Fourati M, Zghal M, Chaker E, et al. Chromomycose: A propos d'une observation. J Mycol Med 2003;13:37-9.

4. Sebaï E, Benmously R, Fazaa B, Chaker E, Zermani R, Kamoun MR. Chromomycosis arising in a Tunisian man. Dermatol Online J. 2005;11:14.

5. Piepenbring M, Mendez C, Espinoza E, Kirschner R, Schöfer H. Chromoblastomycosis caused by Chaetomium funicola: A case report from Western Panama. Br J Dermatol. 2007;157:1025-9.

6. Bonifaz A, Carrasco-Gerard E, Saul A. Chromoblastomycosis: Clinical and mycologic experience. Mycoses. 2001;44:1-2.

7. Minotto R, Bernardi CD, Mallmann LF, Edelweiss MI, Scroferneker ML. Chromoblastomycosis: A review of 100 cases in the state of Rio Grande do Sul, Brazil. J Am Acad Dermatol. 2001;44:585-92.

8. Vijaya D, Kumar BH Chromoblastomycosis. Mycoses. 2005;48:82-4.

9. Esterre P, Pecarrere JL, Raharisolo C, Huerre M. Squamous cell carcinoma arising from chromomycosis. Report of two cases. Ann Pathol. 1999;19:516-20.

10. dos Santos A, Minelli L. Melanoma in a long-standing lesion of chromoblastomycosis. Int J Dermatol. 2006;45:1331-3.

11. Artüz F, Alli N, Lenk N, Güngör E. Purple erythematous plaques on the face and left arm. Arch Dermatol. 1997;133:1027-32.

12. Smith CH, Barker JN, Hay RJ. A case of chromomycosis responding to treatment with itraconazole. Int J Dermatol. 1993;128:436-9.

Copyright by Olfa El Amine El Hadj, et al. This is an open access article distributed under the terms of the Creative Commons Attribution License, which permits unrestricted use, distribution, and reproduction in any medium, provided the original author and source are credited.

Source of Support: Nil, Conflict of Interest: None declared. 